Nat. Hazards Earth Syst. Sci., 10, 923-932, 2010

www.nat-hazards-earth-syst-sci.net/10/923/2010/

(C) Author(s) 2010. This work is distributed under

the Creative Commons Attribution 3.0 License.

\title{
Rapid characterisation of large earthquakes by multiple seismic broadband arrays
}

\author{
D. Roessler, F. Krueger, M. Ohrnberger, and L. Ehlert \\ Department of Earth and Environmental Studies, University of Potsdam, K.-Liebknecht-Str. 24/H27, 14476 Potsdam, \\ Germany
}

Received: 1 December 2009 - Revised: 25 March 2010 - Accepted: 26 March 2010 - Published: 27 April 2010

\begin{abstract}
An automatic procedure is presented to retrieve rupture parameters for large earthquakes along the Sunda arc subduction zone. The method is based on standard array analysis and broadband seismograms registered within $30^{\circ}-$ $100^{\circ}$ epicentral distance. No assumptions on source mechanism are required. By means of semblance the coherency of $P$ waveforms is analysed at separate large-aperture arrays. Waveforms are migrated to a $10^{\circ} \times 10^{\circ}$ wide source region to study the spatio-temporal evolution of earthquakes at each array. The multiplication of the semblance source maps resulting at each array increases resolution. Start, duration, extent, direction, and propagation velocity are obtained and published within $25 \mathrm{~min}$ after the onset of the event. First preliminary results can be obtained even within $16 \mathrm{~min}$. Their rapid determination may improve the mitigation of the earthquake and tsunami hazard. Real-time application will provide rupture parameters to the GITEWS project (German Indonesian Tsunami Early Warning System). The method is applied to the two M8.0 Sumatra earthquakes on 12 September 2007, to the M7.4 Java earthquake on 2 September 2009, and to major subduction earthquakes that have occurred along Sumatra and Java since 2000. Obtained rupture parameters are most robust for the largest earthquakes with magnitudes $M \geq 8$. The results indicate that almost the entire seismogenic part of the subduction zone off the coast of Sumatra has been ruptured. Only the great Sumatra event in 2004 and the M7.7 Java event on 17 July 2006 could reach to or close to the surface at the trench. Otherwise, the rupturing was apparently confined to depths below $25 \mathrm{~km}$. Major seismic gaps seem to
\end{abstract}

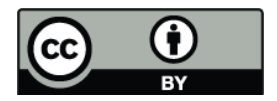

Correspondence to: D. Roessler (d-roessler@web.de) remain off the coast of Padang and the southern tip of Sumatra.

\section{Introduction}

Earthquakes that are sufficiently small compared to the considered wavelengths of the radiated wavefield are described as point sources. Larger earthquakes with finite extent can be described as the superposition of point sources that rupture at different stages of the event. Kinematic source parameters describe the orientation, extent, duration, and rupture propagation of such earthquakes. Their knowledge is important to assess and to mitigate societal risk in the aftermath of destructive events. They are often modelled in detail by inversion of seismic waveforms, aftershock distribution and geodetic observations. Results are, however, often highly nonunique or require considerable amounts of computational effort or time to record aftershocks (hours to days).

Seismic arrays are used to detect and locate earthquakes and seismic structures by increasing the signal-to-noise ratio as compared to single seismic stations (see Rost and Thomas, 2009 , for an overview). Since the megathrust tsunamigenic M9.1 Sumatra earthquake in 2004 (Krüger and Ohrnberger, 2005; Krüger and Ohrnberger, 2005; Ishii et al., 2005) array methods have also found application to determine kinematic parameters of large earthquakes such as rupture extent, direction, duration, and velocity (Krüger et al., 2006; Ishii et al., 2007; Rößler et al., 2008; Zhang et al., 2008; Rößler et al., 2009; Xu et al., 2009). Here we propose a fast and robust method to retrieve such rupture parameters within a few minutes after the event using multiple seismic broadband arrays.

Published by Copernicus Publications on behalf of the European Geosciences Union. 
The method is operational and routinely applied in near-realtime. It was initially developed for the German-Indonesian Tsunami Early Warning System (GITEWS Rudloff et al., 2009). Therefore, we put emphasis on the robustness as well as on computational speed. We demonstrate results for recent large earthquakes along the Sunda arc which are obtained from an ongoing automatic real-time application and previous manual data processing.

\subsection{Theory}

Classical array beamforming assumes coherent signals but uncorrelated noise, plane wave propagation, and equal station timing. Waveforms $x(t)$ may be composed of coherent signals $s(t)$ and uncorrelated noise $n(t), x(t)=s(t)+n(t)$. The beam $b(t)$ is formed by stacking seismograms at time $t$ for a specific slowness vector $\boldsymbol{u}$ which is a property of the considered signal

$b(t)=s(t)+\frac{1}{N} \sum_{i=1}^{N} n_{i}\left(t+\boldsymbol{r}_{i} \boldsymbol{u}\right)$,

with the coordinate vector $\boldsymbol{r}_{i}$ of station with index $i$. In (1) $t$ is the time at a reference station or a reference point that $\boldsymbol{r}_{i}$ is referred to. For uncorrelated noise beamforming increases the signal-to-noise ratio by a factor of $\sqrt{N}$.

The beampower $E(t)$ expresses the energy of the beam within a time window centred around $t$

$$
E(t)=\frac{1}{K+1} \sum_{k=-K / 2}^{K / 2}\left|\frac{1}{N} \sum_{i=1}^{N} x_{i}\left(t+k \Delta t+\boldsymbol{r}_{i} \boldsymbol{u}\right)\right|^{2},
$$

where $k$ is the sample index and $\Delta t$ is the increment of the time within the time window. If $\boldsymbol{u}$ is unknown it can be determined by a grid search maximising $E(t)$.

The plane-wave assumption will be violated with increasing dimension of the array. As a consequence, slowness, $\boldsymbol{u}$, is not equal for all stations. However, large arrays are desired because the spatial resolution of an array increases with aperture (see Rost and Thomas, 2009, for a summary). Therefore we account for curved wavefronts in the global Earth. That is, the term $\left(t+\boldsymbol{r}_{i} \boldsymbol{u}\right)$ in (1) and (2) is replaced by $\left(t_{0}+t_{i}\right)$, where $t_{0}$ is the time at any given hypothetical hypocentre and $t_{i}$ is the traveltime of the considered phase from the hypocentre to station $i$. Travel times $t_{i}$ are computed using a standard spherical Earth model such as ak135 (Kennett et al., 1995) and corrections for ellipticity. Replacing the argument beam power (2) takes the form

$E\left(t_{0}\right)=\frac{1}{K+1} \sum_{k=-K / 2}^{K / 2}\left|\frac{1}{N} \sum_{i=1}^{N} x_{i}\left(t_{0}+k \Delta t+t_{i}\right)\right|^{2}$.

Beampower $E\left(t_{0}\right)$ is an absolute measure of the amplitudes at an array. It depends on hypocentral distance, azimuth as well as on magnitude and mechanism of an earthquake. For large earthquakes the radiated seismic energy may even vary significantly during different parts of the rupture process (e.g. start and stop of the rupture). Therefore, we prefer to use semblance (Neiddell and Turhan Taner, 1971) as a measure of coherency of the wavefield for rupture tracking. Semblance, $S$, is simply beampower (3) normalised by the energy summed over all considered seismograms

$S\left(t_{0}\right)=\frac{1}{N} \frac{\sum_{k=-K / 2}^{K / 2}\left|\sum_{i=1}^{N} x_{i}\left(t_{0}+k \Delta t+t_{i}\right)\right|^{2}}{\sum_{k=-K / 2}^{K / 2} \sum_{i=1}^{N} x_{i}^{2}\left(t_{0}+k \Delta t+t_{i}\right)}$.

Due to the normalisation, $0 \leq S(t) \leq 1$ and is independent of individual signal amplitudes. For uncorrelated noise $S \approx$ $1 / N$ but significantly higher for coherent signals $S$ (Douze and Laster, 1979).

By Eqs. (3) and (4) seismograms are migrated to any hypothetic source position and time. The semblance is noncentrally F-distributed (Douze and Laster, 1979). Therefore, semblance relates to probability of seismic energy being radiated from a given source location and at $t_{0}$. Semblance relates to probability via $F$-statistics (Douze and Laster, 1979). It therefore provides a probability that, seen at the given array, seismic energy was radiated at the given source point and time. If the considered phase was generated at the assumed location and time, semblance will be high and $S>1 / N$, but low otherwise.

The semblance calculation is easily extended from a single source point and time to a large area or volume and many time steps giving time-dependent semblance source maps. For such an area or volume the traveltimes $t_{i}$ are calculated from any given source point to all stations. Semblance $s\left(t_{0}\right)$ is computed for all points. By shifting $t_{0}$ a time series of semblance source maps is obtained. If an earthquake occurred within the assumed area or volume this directly allows to image the spatio-temporal evolution and to track the rupture during an earthquake. In principle this method can be applied continuously to the whole Earth. Computational effort decreases by constraining region and time. A rough hypocentre estimate must be provided to define a source region. For earthquakes in many regions hypocentres are available within a few minutes $(<10 \mathrm{~min})$ after an event initiated (GEOFON, http://geofon.gfz-potsdam.de Hanka et al., 2000).

The spatial resolution of a seismic array increases with number of stations, array aperture and the frequency bandwidth of the signal (see Rost and Thomas, 2009, for a summary). However, as array aperture increases, the frequency, above which waveforms loose coherency, decreases. This can be attributed to increasing structural inhomogeneity, the effect of radiation pattern and source directivity which changes the waveforms (Aki and Richards, 2002). As a result image resolution of arrays that are too large (e.g. the full global network) may be reduced compared to smaller arrays (Xu et al., 2009).

The method is applied to large and very large earthquakes which typically show dominant frequencies of the source 
spectra below $0.1 \mathrm{~Hz}$ for $P$ waves. We found by manual inspection of the $P$ waveforms of such events that arrays as large as $4000 \mathrm{~km}$ aperture can be used.

For a single array the distance/azimuth resolution depends mainly on aperture but depending on the actual number of stations and the interstation distances aliasing may be a problem for a specific array configuration. The time resolution of a single array is directly linked with its slowness resolution and typically is smeared along the great circle arc connecting the source and the receiver array.

The polarity of a $P$ wave is determined by the earthquake source mechanism and the take-off direction of the wave. Polarity reversals destroy coherency of waveforms and reduce semblance if waveforms are stacked. They occur near the nodal planes of the radiated $P$ waves. A single regional array by chance may lay at or near the nodal plane of the specific mechanism.

To overcome the above mentioned problems of single arrays we use a distributed set of large aperture regional arrays surrounding the hypothetical source region (compare Fig. 1). Each array will then give an individual semblance map. Semblance is a one sided positive function of waveform coherency independent of the overall polarity of the incoming waveforms. We can therefore avoid the polarity problem due to the in general unknown source mechanism by summing or multiplying the semblance source maps of the different arrays for a specific source time. Because semblance can be related to likelihood we feel that multiplication of the semblance values of different arrays is more appropriate than summation. The multiplication also corresponds to a multiplication of the transfer functions of the arrays. Ideally, their central lobe should be at the same position but the side lobes are at different positions. The multiplication leads therefore to a more distinct central lobe (that refers to the actual source signal) and to the suppression of side lobes. Due to heterogeneity of the Earth, the single array localisations may deviate slightly from actual hypocentres. By multiplication this error is reduced.

Taken all facts together the combined semblance

$$
S\left(t_{0}\right)=\prod_{i=1}^{M} S_{i}\left(t_{0}\right)
$$

has increased resolution in space and time and more stability than the single array estimates ( $M$ is the number of arrays). The resulting combined semblance maps are related to a joint probability that an earthquakes occurred in the area at the given $t_{0}$.

\subsection{Station selection}

For rapid rupture tracking of large earthquakes, semblance analysis is applied assuming the first-arriving direct $P$ waves originate from distances between $30^{\circ}$ and $100^{\circ}$. Within this distance range $P$ waves are well separated from strong

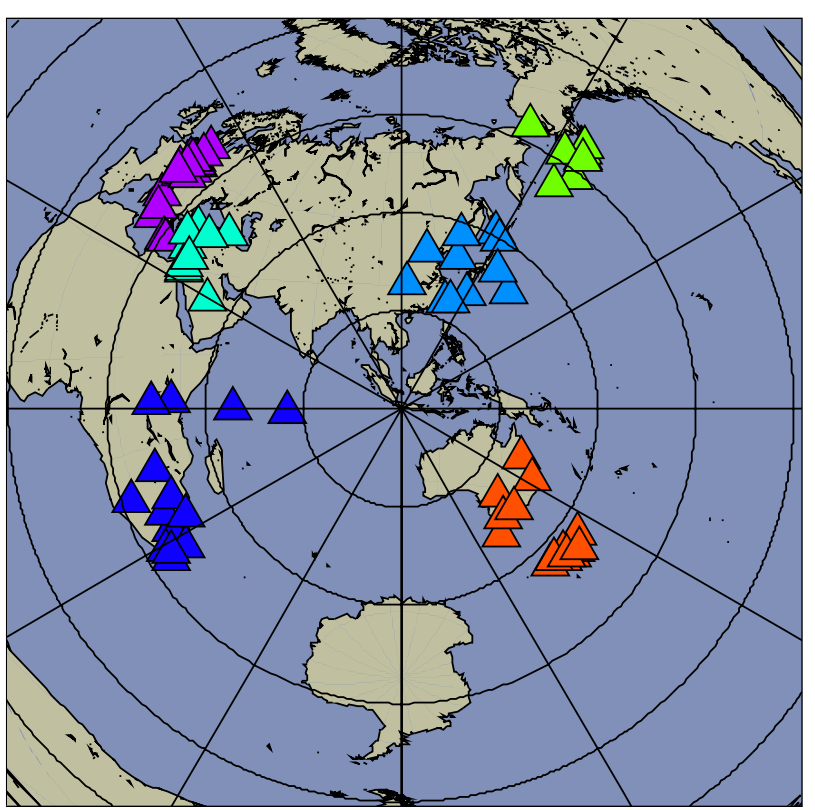

Fig. 1. Map of stations used for semblance analyis of the $M 7.4$ Java earthquake on 2 September 2009 (centre of the map). Stations are located within epicentral distances of $30^{\circ}-100^{\circ}$. Colours indicate the different arrays used for data processing.

later body wave phases and surface waves. At smaller distances the wavefield is more complicated by triplications in $P$ due to upper-mantle discontinuities. At greater distances $P$ turns into $P_{\text {diff }}$ which is connected with waveforms distortion and rapid amplitude decay. The restriction to teleseismic $P$ waves determines the minimum time needed for computation. Using $S H$ waves which arrive much later than $P$ would significantly increase waiting time. Therefore, $S H$ waves are not considered for automatic near-real-time application.

We use seismograms of high quality seismic broadband stations. All stations were manually selected and checked upon their broadband character and data quality in the prepraratory phase of the automatic online processing. They are merged to six virtual large-aperture regional arrays which are combined during processing (Fig. 1).

\subsection{Data processing and implementation}

Broadband data are acquired continuously using SeedLink, saved to disk, and processed automatically. Arrays are predefined to optimise azimuthal coverage for earthquakes along the Sunda arc. We associate stations to six separate arrays in regions of Europe, around the eastern mediterenean sea, east Asia, Alaska and eastern Russia, Africa, and Australia and New Zealand (compare Fig. 1).

We continuously receive earthquake alerts including magnitude and preliminary hypocentre from GEOFON via email and the SeisComp system. Semblance analysis is routinely started for all events with magnitude $M \geq 5.5$. Based on the 
preliminary hypocentres, stations are selected within epicentral distances of $30^{\circ}$ to $100^{\circ}$. A $10^{\circ} \times 10^{\circ}$ wide area around the epicentre at the hypocentre depth defines the target area. Source depth is kept constant at hypocentre depth due to limited depth resolution (teleseismic $P$ waves leave the source region with steep incidence angles). Data acquisition starts at $19 \mathrm{~min}$ and $46 \mathrm{~s}(1186 \mathrm{~s})$ after source time to account for maximum travel times of the $P$ waves $(\approx 826 \mathrm{~s}$ ), up to 300 s rupture duration, and $60 \mathrm{~s}$ data latency. The data latency is the time needed to transmit seismogram data from the recording station to the processing computer. It varies between seconds and sometimes minutes.

We only consider vertical component broadband seismograms where the $P$ waves are most prominent. Incoming raw seismograms have different sampling frequencies in the range of $20-100 \mathrm{~Hz}$ which need to be homogenised. For efficient semblance analysis data are downsampled to $10 \mathrm{~Hz}$ and bandpass filtered between 0.01 and $4 \mathrm{~Hz}$. Starting $200 \mathrm{~s}$ before actual source time, semblance is calculated for the selected area and for 100 time steps $\left(t_{0}\right)$ in intervals of $5 \mathrm{~s}$. For the separate arrays all data are processed and the semblance source maps are computed on separate client nodes on a highperformance computer cluster.

A master node collects the semblance source maps of the individual arrays. They are combined by pointwise multiplication (see Fig. 2 and Ohrnberger and Krüger, 2005; Rößler et al., 2008) as mentioned above.

\subsection{Parameter extraction}

The maxima of the combined semblance source maps are considered to image the most likely position of the major seismic energy release at a given time $t_{0}$. They are used to retrieve rupture parameters such as start, duration, length, direction, and velocity. This is especially useful in the case of unilateral rupturing but may be non-unique for bilateral ruptures after the semblance computations are finished.

Start and duration of the rupture are determined using a conventional sta/lta trigger applied to the time series of the maximum semblance value over all grid points. Sta and lta define the moving short-term and long-term semblance averages within $15 \mathrm{~s}$ and $100 \mathrm{~s}$, respectively. Rupture length is calculated from the greatest distance between two maxima within the time of rupturing. Duration and rupture length give an average rupture velocity. The direction is approximated from mean azimuth of the semblance maxima with respect to epicentre. The horizontal rupture area is also estimated. However, accuracy strongly depends on the actual data coverage, rupture propagation, and source mechanism. Data processing was developed and tested manually. Since 2008 the algorithm has been implemented for automatic real-time application. A summary image of the results is published in the internet (http://www.geo.uni-potsdam.de/arbeitsgruppen/
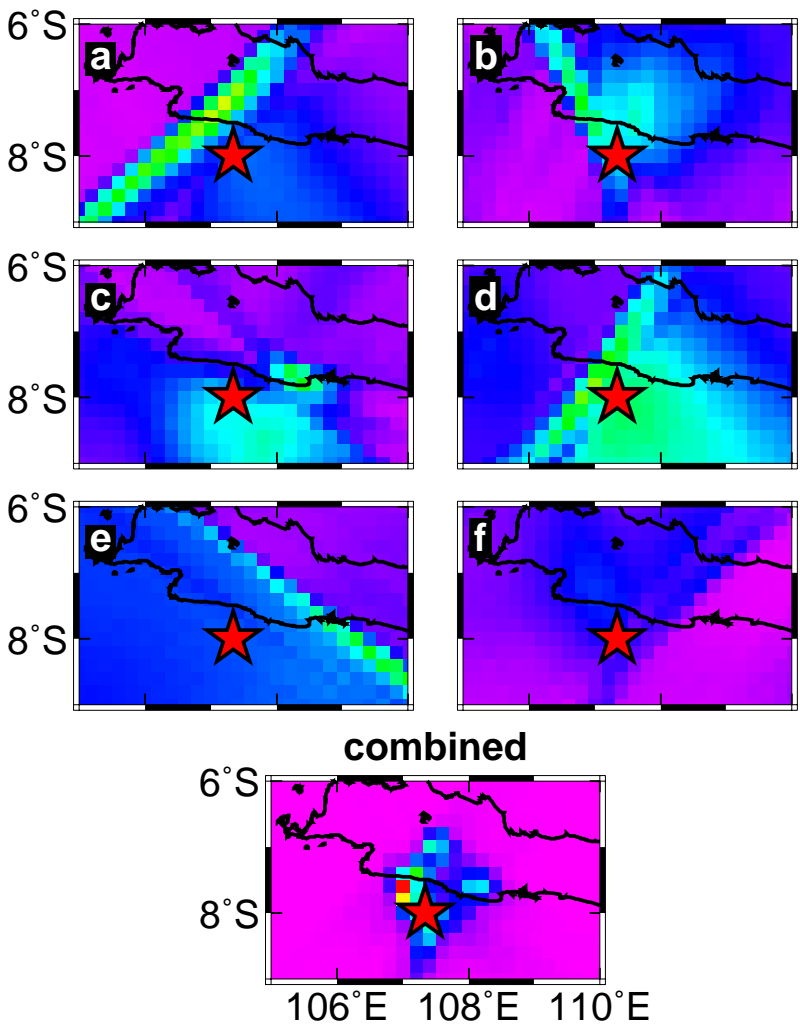

Fig. 2. Combination for semblance source maps by multiplication at the onset of the M7.4 Java earthquake on 2 September 2009. Assuming source time, semblance source maps are computed at arrays in (a) Europe, (b) Africa, (c) East Asia, (d) eastern Mediterranean Sea (e) Alaska, and (f) Australia, New Zealand (compare Fig. 1). Colours indicate normalised semblance.

geophysik_seismologie/forschung/ruptrack/index.php) for the largest earthquakes.

Although semblance computations are relatively time efficient, computational effort increases with the number of available seismograms. Typically, the computation of semblance source maps and rupture parameters takes about $5 \mathrm{~min}$. If earthquake alerts are received before the $P$ waves arrive at $100^{\circ}$ epicentral distance then the results are published within about $25 \mathrm{~min}$ after the origin time of the earthquake.

\section{Examples}

Although rupture tracking is routinely performed for earthquakes worldwide we have optimised the performance to subduction-zone earthquakes along the Sunda arc near Java and Sumatra. Here we concentrate on the largest, most recent earthquakes that occurred off the coast of Sumatra, the two adjacent M8.0 Bengkulu events on September 12, 2007, 11:10 and 23:49 (Figs. 3, 4) and on the M7.4 Java 

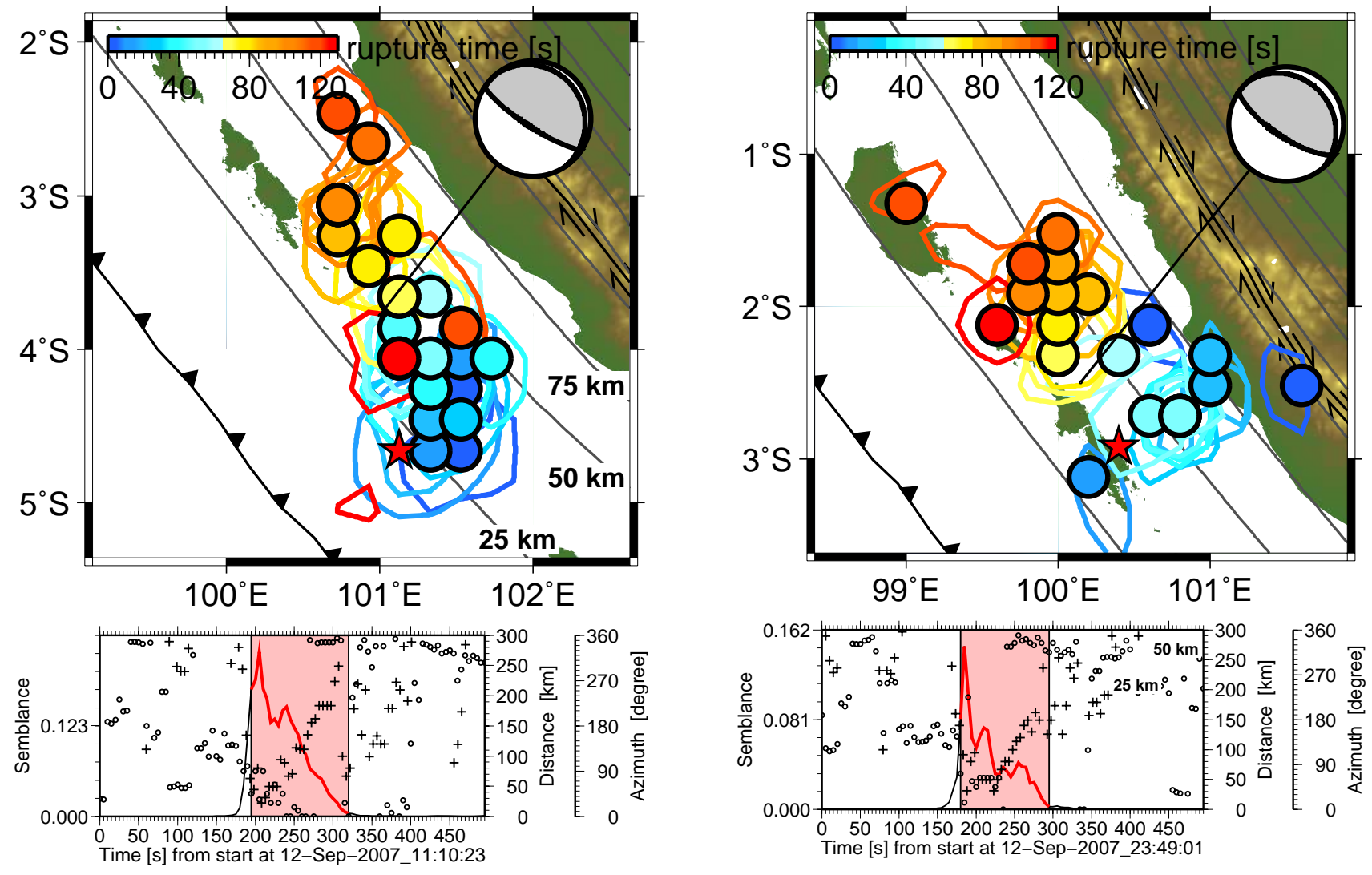

Fig. 3. Results for the M8.0 Sumatra earthquake on 12 September 2007, 11:10. Top: epicentral area with maxima (dots) and 0.9 contour lines of normalised semblance source maps. Colours indicate rupture time. Star: epicentre (GEOFON). The focal mechanism shows the centroid moment tensor solution (Ekström and Nettles, 2009). Grey contour lines indicate slab depth (Gudmundsson and Sambridge, 1998). Bottom: time series of maximum of semblance maxima over all grid points (black/red line), distance (crosses) from and azimuth (circles) to epicentre from multiplied semblance source maps. Origin time (GEOFON) is a $200 \mathrm{~s}$. Values at times outside the interval marked in red are attributed to noise and phases follwing the $P$ waves. The red line and area: time interval when sta/lta trigger indicates rupturing.

earthquakes on 2 September 2009 (Fig. 6). The two Benkulu events caused minor local tsunamis. The Java event is located near the tsunami earthquake on 17 July 2006 . We also summarise the results for other major events of the region since the year 2000 (Fig. 7 and Table 1). Their rupture parameters where retrieved applying semblance analysis and similar array configurations as in Fig. 1.

The Sunda arc is a major subduction zone at which the Indo-Australian plate is subducted underneath the Sunda plate at a convergence rate of up to $6 \mathrm{~cm} / \mathrm{yr}$ (Subarya et al., 2006). Within this region a number of major $M>7$ earthquakes have occurred since the destructive megathrust $M 9.1$ earthquake on 26 December 2004. Two other events on

Fig. 4. As in Fig. 3 but for the nearby M8.0 earthquake on 12 September 2007, 23:49.

28 March 2005 and on 17 July 2006 caused tsunamis that were destructive along nearby coastlines. Although most of these very large earthquakes show dip in the direction of the subduction there are also examples for rotated mechanisms (Fig. 7).

Both Benkulu events are typical subduction zone thrust earthquakes with strike being parallel to the subduction front. The onset of the first M8.0 event at 11:10 is well defined by a rapid semblance increase. It is caught by the sta/lta trigger at $t_{0}=195 \mathrm{~s}$ close to the GEOFON origin time at $t_{0}=200 \mathrm{~s}$ (Fig. 3). The onset location given by the first triggered semblance maximum is located near the GEOFON epicentre which lies well within the 0.9 combined semblance contour line. Combined semblance is highest near the onset but decreases as the rupture progresses. This decrease may be caused by simultaneous rupture of different parts of the fault. After the onset, semblance remains high for $125 \mathrm{~s}$. This is interpreted as the total rupture duration. The rupture propagates over at least $200 \mathrm{~km}$ to the north at a velocity of about $2 \mathrm{~km} / \mathrm{s}$. Interestingly, the centroid location (Ekström and Nettles, 2009) is located at the centre of the rupture. Assuming that rupturing occurs along the slab interface it seems to reach progressively greater depth of $50-60 \mathrm{~km}$. It 
Table 1. Results for selected major earthquakes along the Sunda arc since 2000. Hypocentre parameters and magnitudes are obtained from GEOFON (* http://geofon.gfz-potsdam.de) or USGS (** http://earthquake.usgs.gov/eqcenter).

\begin{tabular}{|c|c|c|c|c|c|c|c|c|c|}
\hline $\begin{array}{l}\text { hypocentre } \\
\text { time }\end{array}$ & $\begin{array}{r}\text { latitude } \\
\qquad\left[{ }^{\circ} \mathrm{N}\right]\end{array}$ & $\begin{array}{r}\text { longitude } \\
{\left[{ }^{\circ} \mathrm{E}\right]}\end{array}$ & $\begin{array}{r}\text { depth } \\
{[\mathrm{km}]}\end{array}$ & $M w$ & $\begin{array}{r}\text { duration } \\
{[\mathrm{s}]}\end{array}$ & $\begin{array}{r}\text { length } \\
{[\mathrm{km}]}\end{array}$ & $\begin{array}{r}\text { velocity } \\
{[\mathrm{km} / \mathrm{s}]}\end{array}$ & direction & $\begin{array}{l}\text { dominant } \\
\text { character }\end{array}$ \\
\hline $04 / 06 / 2000^{* *}$ & -4.7 & 102.1 & 33 & 7.9 & 100 & 200 & 2 & SE & unilateral \\
\hline $24 / 12 / 2004^{* *}$ & 3.3 & 95.9 & 30 & 9.1 & 500 & 1200 & 2.8 & $\mathrm{~N}$ & unilateral \\
\hline $28 / 03 / 2005^{* *}$ & 2.1 & 97.0 & 30 & 8.7 & 130 & 200 & 2 & trench-parallel & bilateral \\
\hline $17 / 07 / 2006^{* *}$ & -9.2 & 107.3 & 34 & 7.7 & 170 & 150 & 1 & $\mathrm{E}$ & unilateral \\
\hline 08/08/2007** & -6.1 & 107.7 & 301 & 7.6 & $<50$ & & & & stationary \\
\hline 12/09/2007 11:10* & -4.6 & 101.3 & 32 & 8.0 & 120 & 200 & 2 & $\mathrm{~N}$ & unilateral \\
\hline 12/09/2007 23:49* & -2.6 & 100.7 & 28 & 8.0 & 110 & 150 & 2 & $\mathrm{~N}$ & unilateral \\
\hline 02/09/2009* & -8.0 & 107.3 & 62 & 7.4 & $<40$ & & & & stationary \\
\hline
\end{tabular}

is important to note that we have no indication that rupturing occurred shallower than $25 \mathrm{~km}$ depth. This slab depth interval coincides at the surface approximately with the trenchparallel Mentawai fault. This poses the question whether or not the shallower part of the subduction interface was loaded by the event. The latter would increase the potential for another shallow very large event with great tsunami risk.

The second very large M8.0 Benkulu earthquake happened only a few hours later on 23:49 of the same day. It originated at the northern edge of the first event and continued to propagate northwards (Fig. 4). As before the onset is well defined by high semblance. Rupture duration and length are $100-110 \mathrm{~s}$ and $160 \mathrm{~km}$, respectively. The northernmost semblance maximum is interpreted as an outlier. As before, rupturing seems to be bounded between depths of 25 to $75 \mathrm{~km}$. Contour lines concentrate near and downdip from the start and at the end of the rupture. In addition, semblance is increased towards the end of the event at $t_{0}=260 \mathrm{~s}$ following a local minimum. This indicates relatively smooth rupturing with only little variations in slip. The observations as well as the extent of the rupture retrieved for both Benkulu events are compatible with finite source modelling published by the USGS http://earthquake.usgs.gov/eqcenter/eqinthenews.

The M7.4 Java earthquake on 2 September 2009 seems remarkable as it shows reverse faulting with strike perpendicular to the subduction trench (Fig. 6). The size and focal depth of the event are appropriate to study some limitations of the multiple array semblance analysis.

The German Gräfenberg array, located at about $100^{\circ}$ epicentral distance, has recorded high-quality $P_{\text {diff }}$ and $S_{\text {diff }}$ phases (see Fig. 5). Single $P_{\text {diff }}$ phases show seismic energy concentrated near the phase onset but coherent waveforms for about $60 \mathrm{~s}$ with clear additional onsets after about $30 \mathrm{~s}$ and $50 \mathrm{~s}$. The stack of the 13 single traces (beam) shows that these phases have the same or very similar slowness. In contrast, the $S_{\text {diff }}$ wavetrain is shorter and can be followed for only $40 \mathrm{~s}$ with an additional coherent phase about $30 \mathrm{~s}$ after the arrival of $S_{\text {diff. The different lengths of the wave- }}$ trains indicate that the rupture duration is not longer than
$40 \mathrm{~s}$. Therefore, the phases at $25 \mathrm{~s}$ and $55 \mathrm{~s}$ on the vertical and the transverse component seismograms in Fig. 5 indicate the start and the termination of the rupture. Given the depth of the event (Table 1 ) the depth phases $p P_{\text {diff }}$ and $s P_{\text {diff }}$ arrive 17.5 and $24.5 \mathrm{~s}$, respectively, after $P_{\text {diff. They interfere }}$ with the ongoing wavetrain of $P_{\text {diff }}$ and the phase at $75 \mathrm{~s}$ on the vertical component can be interpreted as the depth phase of the stopping phase. $s S_{\text {diff }}$ arrives $30.5 \mathrm{~s}$ after $S_{\text {diff }}$ but is not clearly visible on the transverse components or interferes with $S_{\text {diff. }}$

Since only vertical components are used for real-time semblance analysis their long duration is likely to be caused by late structure related phases originating in the source region. Semblance clearly increases and the event onset is triggered at $195 \mathrm{~s}$ (Fig. 6), $5 \mathrm{~s}$ before origin time (GEOFON). After the onset, semblance remains high for $65 \mathrm{~s}$ where the automatic analysis defines the event termination. The location of the semblance maximum at onset is offset by about $0.5^{\circ}$ from the epicentre. This mislocation reduces within the following $30 \mathrm{~s}$. According to the seismogram interpretation, the actual rupture duration is about $30 \mathrm{~s}$. This period appears too short and the rupture extent too small to resolve other rupture parameter than the event onset. Thereafter, areas of high semblance scatter around the epicentre and spread in western and eastern direction. The greatest apparent extent is reached in WNW direction, $50 \mathrm{~s}$ after the start of the rupture and $88 \mathrm{~km}$ away from the epicentre. Such scatter is typical for bilateral earthquakes. Here, it seems to be an artefact due to depth phases.

The interpretation of results is generally difficult for events of this size. From our experience smaller earthquakes $(M<$ 7) can be detected and localised but resolution is insufficient to resolve other rupture parameters. Tractable resolution can be expected for shallow earthquakes with $M \geq 8$ and slow earthquakes with large rupture areas. Furthermore, rupture parameters are best resolved for unilateral earthquakes.

We have also analysed other earthquakes of the region for which we summarise the results (see Table 1 and Fig. 7). The 7.9 event on 4 June 2000, off the coast of southern Sumatra 

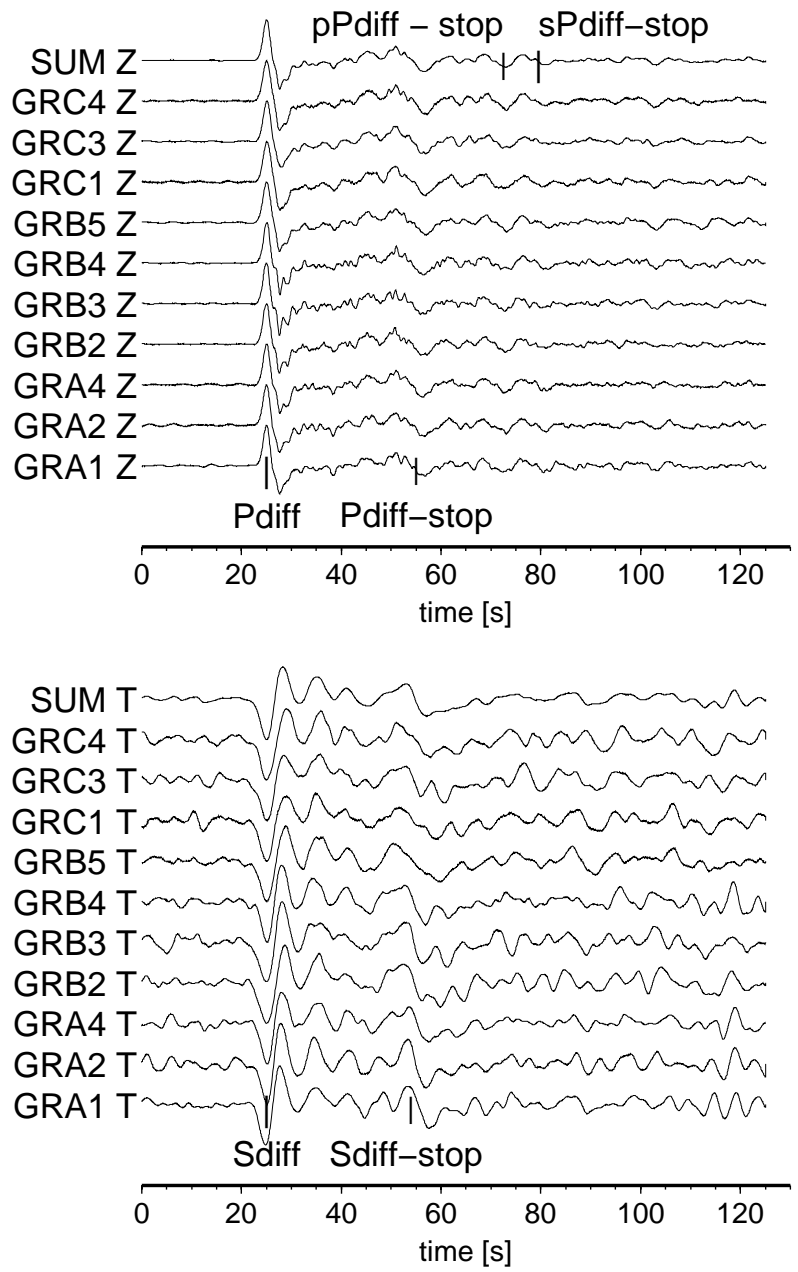

Fig. 5. Raw velocity seismograms at stations of the Gräfenberg array, Germany, for the M7.4 Java earthquake on 2 September 2009. Traces are normalised and aligned to the onsets of the $P$ waves (top, vertical component) and of the $S$ waves (bottom, transverse component). The summed trace is on the top of each seismogram ensemble. The phases near $55 \mathrm{~s}$ are interpreted as the stopping phase ( $P_{\text {diff }}$ and $S_{\text {diff }}$ ) defining the end of the rupture. The arrivals of the depth phases ( $p P_{\text {diff }}$ and $s P_{\text {diff }}$ ) related to the stopping phases are indicated on the sum of the vertical components.

propagated unilaterally to the southwest over $200 \mathrm{~km}$ and $100 \mathrm{~s}$ at a rupture speed of $2 \mathrm{~km} / \mathrm{s}$. It is directly adjacent to the Bengkulu earthquakes in 2007. The rupture seems to be also bounded in the same depth range without reaching the ocean floor. The great M9.1 Sumatra earthquake on 26 December 2004, propagated northwards over $1200 \mathrm{~km}$ and approximately $500 \mathrm{~s}$ at a constant velocity of about $2.8 \mathrm{~km}$ (Krüger and Ohrnberger, 2005; Krüger and Ohrnberger, 2005). It almost certainly reached the ocean floor at the trench. On 28 March 2005, the M8.7 earthquake started as a bilateral rupture which continued further to the south. Total rupture time and extent is $130 \mathrm{~s}$ and $200 \mathrm{~km}$, respectively. The $M 7.7$
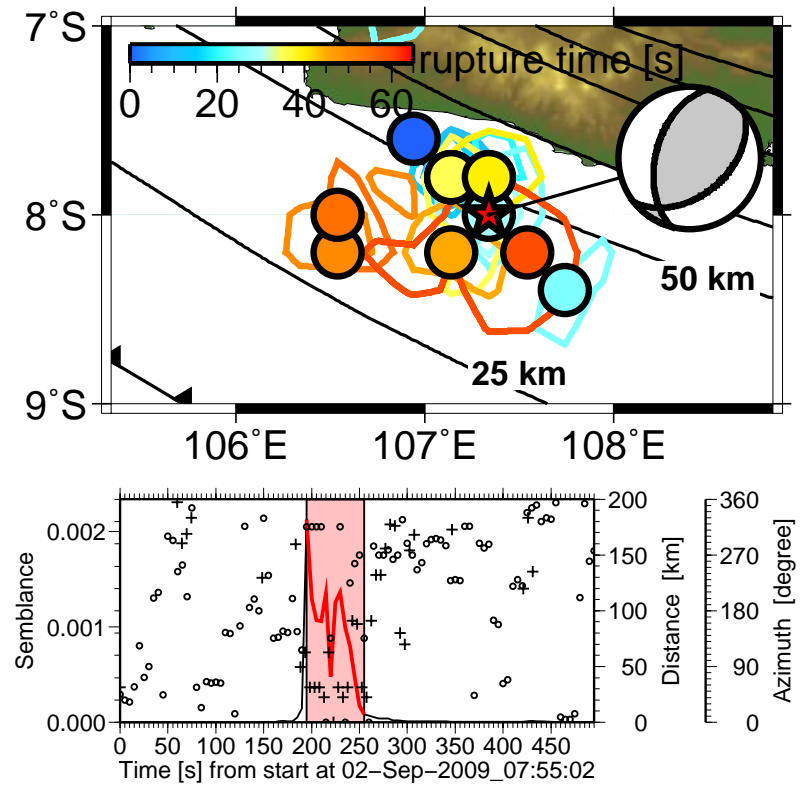

Fig. 6. As in Fig. 3 but for the M7.4 Java earthquake on 2 September 2009 .

tsunami earthquake on 17 July 2006, propagated unilaterally to the east after an initial phase of bilateral rupture growth. Rupture velocity was low at only $1 \mathrm{~km} / \mathrm{s}$ for about $170 \mathrm{~s}$. With a lateral extent of $150 \mathrm{~km}$ it could reach to the trench. The deep M7.6 earthquake on 8 August 2007, could be well located. Rupture duration was less than $50 \mathrm{~s}$. Due to the great depth and the vertical fault orientation the apparent rupture area is relatively small and was not resolved.

\section{Discussion}

Semblance as a measure of waveform coherency is used to evaluate beamforming and the occurrence of earthquake rupturing. Compared to beampower, which is often used, semblance evaluates waveforms. It is less dependent on amplitudes of individual traces and therefore less prone to station dependent noise or erroneous true-amplitude recovery of seismograms. This makes semblance more appropriate in this application.

Unequal polarities of the considered phases at different station prevents constructive stacking of seismograms. In the case of $P$ waves, polarities depend on the actual earthquake source mechanisms and the direction of the wave departing from the source. Evaluation of seismograms within a global station array therefore requires the correction for polarity reversals or for the source mechanism which must be determined or known a priori. Otherwise, results may be obscured. The polarity corrections add extra computational effort which may prevent fast rupture tracking. 


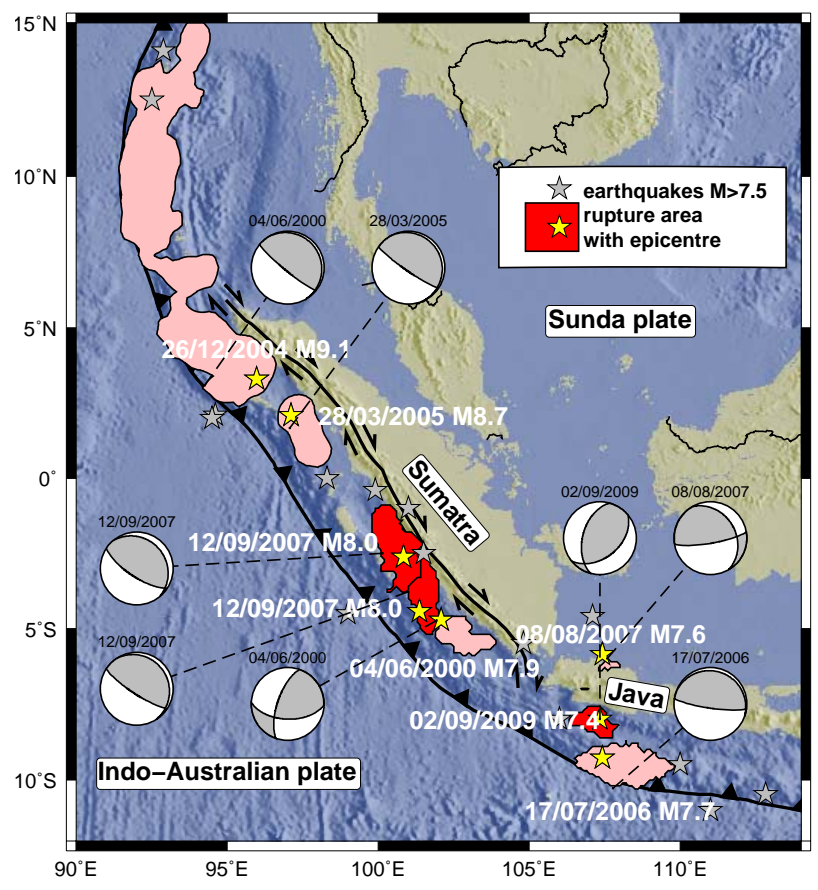

Fig. 7. Map of rupture areas for events in Table 1 along with centroid moment tensor solutions (Ekström and Nettles, 2009). Areas in red show the rupture areas of the events discussed in this paper. Areas in pink show the results for selected events since 2000. Blue stars show epicentres of other large earthquakes, $M>7.5$, in this area since 1900 .

By the combination of well-placed separate arrays instead of one global array, such polarity correction can be avoided. The considered stations are chosen such that polarity reversals within the individual arrays are unlikely for subduction earthquakes along wide regions of the Sunda arc (compare Fig. 1). If such polarity reversals occur, semblance will be low and uncorrelated at the single array. Even in this case, rupture tracking will remain feasible by the array combination if the polarities within the remaining arrays are consistent. The resolution, however, may be reduced. Therefore, the combination of single arrays seems more robust for realtime application than the single global array if the source mechanism is not accounted for.

For traveltime calculations, $P$ waves and constant depth as given by the hypocentre estimate are assumed. Since depth resolution is insufficient, the automatic analysis is only applied to resolve the horizontal extent of the rupture. During beamforming, the signals of phases that have different slownesses than the $P$ waves are suppressed. Depending on source depth and epicentral distance the slowness of the $P$ wave are similar to the $p P$ and $s P$ depth phases and differential times $P-p P, P-s P$ may be small. Therefore, depth phases may not be sufficiently suppressed. Furthermore, amplitudes of $p P$ and $s P$ waves can be large compared to direct $P$. This sometimes may give rise to locating energies of depth phases using slowness and traveltimes of $P$ waves into the source region. The resulting bias is reflected in shifts of the occurrence time of a particular source point, less in the location. This may lead to increased semblance values at later times corresponding to the traveltime differences. For deeper earthquakes the depth phases are well separated from the $P$ waves resulting in distinct semblance peaks. This separation may be used to discriminate between shallow and deep earthquakes. On the other hand, increased semblance due to depth phases may lead to apparently longer rupture duration. This is most important for shallow earthquake were the slowness differences are smallest, for small earthquakes, and for earthquakes with a duration similar to the traveltime differences (compare example in Fig. 6). Both effects at present require manual inspection.

Rapid rupture characterisation of shallow $M \geq 8$ earthquakes along the Sunda arc is of prime importance for tsunami early warning. The automatic retrieval of start time, duration, extent, direction, and propagation velocity of the rupture is found reliable for such events. Single semblance maxima give a spatial resolution of about $0.5^{\circ}-1^{\circ}$. The series of maxima provides an image of the rupture that can be evaluated. The estimation of the rupture area depends on a calibration of the shape of the semblance source maps. Results for smaller earthquakes in the range $7 \leq M<8$ strongly depend on hypocentre as well as on data availability and quality. A high-quality image of the rupture was achieved for the M7.7 Java earthquake on 17 July 2006 (Krüger et al., 2006) by manual data processing, at that time state-of the art. For the smaller M7.4 event on 2 September 2009, the onset and upper estimates of the extent and the duration were obtained. Unique event detection is often possible for $M \geq 6$ earthquakes but usually fails below. The application of the method to other regions of the world requires a different array configuration.

The computations also improve with data availability which is limited by the data latency of individual stations. Owing to the goal for rapid rupture characterisation only data latencies of up to $60 \mathrm{~s}$ are considered. However, seismograms for some stations are available first at a later time. Therfore, computations are often repeated. This generally improves the results.

So far the automatic results are obtained and published within about $25 \mathrm{~min}$. Latest developments aim to increase computational efficiency. After coding the algorithm as an integrated part of the new Seiscomp3 software package (Weber et al., 2007) rupture parameters are obtained within 22 min after the onset of the event. Preliminary parameters with lower resolution can be achieved even within $17 \mathrm{~min}$ when only stations up to $60^{\circ}$ epicentral distance are considered. After final testing, results will be made online in the near future.

Based on our results (Fig. 7) we find that almost the entire coastal strip to the west of Sumatra has been ruptured by large subduction-related thrust earthquakes $(M \geq 7.5)$ since 
2000. Three areas that obviously form seismic gaps remain: between the 2000 earthquake and the tip of the Sumatra fault off the coast of southern Sumatra, off the coast of Padang between the 2005 Nias earthquake and the 2007 Bengkulu earthquakes, and the whole stretch between the trench and the up-dip extent of the aforementioned earthquakes to the south of the M9.1 Sumatra-Andaman earthquake in 2004. The seismic gap off the coast of Padang was possibly reduced by the $M 7.7$ event on 30 September 2009 (GEOFON). This raises the question for the state of the remaining slab surface close to the trench (compare Fig. 7). Brittle behaviour and increased load of this part of the subduction would increase the tsunami threat due to large shallow rupture.

It seems that the tsunamigenic potential of an earthquake depends also on the location and the rupture mechanism. Both the Sumatra-Andaman and the Java earthquakes in 2004 and 2007 could reach to or close to the trench. This proximity to the trench and the exceptional low rupture velocity of the Java earthquake in 2006 possibly supported the generation of a destructive local tsunami. On the contrary, the two M8.0 Sumatra earthquakes in September 2007 apparently ruptured only at depths below $25 \mathrm{~km}$ and could not generate major tsunamis.

\section{Conclusions}

We have presented a method to retrieve rupture paramters of large earthquakes along the Sunda arc automatically in a real-time fashion. The method is based on direct $P$ waves at separate large-aperture seismic broadband arrays within teleseismic epicentral distances of $30^{\circ}$ to $100^{\circ}$. It evaluates the semblance as a measure of coherency of waveforms to determine the location and the evolution of earthquake rupturing. The semblance source maps resulting from individual arrays are combined by multiplication. This increases resolution. Results are less dependent on source mechanisms than for a single global array. For shallow $M \geq 8.0$ events start, duration, extent, direction, and velocity of the rupture are determined with confidence. Results for smaller earthquakes depend on rupture properties, location, and data. The retrieved rupture parameters can help to evaluate and mitigate the earthquake and tsunami hazard.

We have presented automatic applications of the method to the two $M 8$ earthquakes on 12 September 2007, off the coast of Sumatra and the M7.4 earthquake on 2 September 2009, off the coast of Java. For the two Sumatra events, their start, duration, extent, propagation direction, and velocity of the rupture could be retrieved. They show almost trench-parallel, northward rupturing at about $2 \mathrm{~km} \mathrm{~s}^{-1}$ that lasted more than $100 \mathrm{~s}$ extending up to $200 \mathrm{~km}$. For the smaller Java event only the start and an upper limit of the duration $(<40 \mathrm{~s})$ was found with confidence. Analysis of the other large $(M>7.5)$ thrust earthquakes of the region show that almost the entire subduction zone off the coast of western Sumatra has under- gone rupturing since 2000. Seismic gaps, however remain to the south of Nias island and at the southern tip of Sumatra probably leaving the region at high earthquake risk. Only the great Sumatra earthquake in 2004 and the Java earthquake in 2007, both tsunamigenic, could reach to or close to the trench. Comparing rupture locations and the RUM model (Gudmundsson and Sambridge, 1998) we find that the other events where confined to depths below $25 \mathrm{~km}$.

Retrieved parameters are published and can be used to constrain seismic and tsunami hazard along the Sunda arc. Therefore, the application will be an intergrated part of GITEWS (Rudloff et al., 2009). At present, the results are available within $25 \mathrm{~min}$ after event onset. Future developments will reduce computation effort to less than $22 \mathrm{~min}$. By limiting the observations to $30-60^{\circ}$ epicentral distance first estimates can be provided even within $17 \mathrm{~min}$.

Acknowledgements. Real-time data were provided by GEOFON (Deutsches GeoForschungszentrum GFZ) and IRIS (http://www.iris.edu). This work received funding through the GITEWS project (German Indonesian Tsunami Early Warning System), Grant 03TSU01. We thank the editor and the reviewers for their comments and very stimulating reviews that helped to improve the manuscript.

Edited by: A. Rudloff

Reviewed by: A. Hutko and another anonymous referee

\section{References}

Aki, K. and Richards, P.: Quantitative seismology, University Science Books, Sausalito, 2002.

Douze, E. J. and Laster, S. J.: Statistics of semblance, Geophysics, 44, 1999-2003, doi:10.1190/1.1440953, short Note, 1979.

Ekström, G. and Nettles, M.: The Global CMT Project, online available at: http://www.globalcmt.org, last access: October 2009, 2009.

Gudmundsson, O. and Sambridge, M.: A regionalized upper mantle (RUM) seismic model., J. Geophys. Res., 103, 7121-7136, 1998.

Hanka, W., Heinloo, A., and Jaeckel, K.-H.: Networked Seismographs: GEOFON Real-Time Data Distribution, Orfeus Newsletter, 2, 24, http://www.orfeus-eu.org/Organization/Newsletter/ vol2no3/geofon.html, 2000.

Ishii, M., Shearer, P., and Vidale, J.: Extent, duration and speed of the 2004 Sumatra-Andaman earthquake imaged by the Hi-Net array, Nature, 435, 933-936, doi:10.1038/nature03675, 2005.

Ishii, M., Shearer, P. M., Houston, H., and Vidale, J. E.: Teleseismic $P$ wave imaging of the 26 December 2004 SumatraAndaman and 28 March 2005 Sumatra earthquake ruptures using the Hi-net array, J. Geophys. Res., 112, B11307, doi:10.1029/ 2006JB004700, 2007.

Kennett, B., Engdahl, E., and Buland, R.: Constraints on seismic velocities in the Earth from travel times, Geophys. J. Int., 122, 108-124, 1995.

Krüger, F. and Ohrnberger, M.: Tracking the rupture of the $M_{W}=$ 9.3 Sumatra earthquake over $1150 \mathrm{~km}$ at teleseismic distance, Nature, 435, 937-939, doi:10.1038/nature0369kao, 2005. 
Krüger, F., and M. Ohrnberger: Spatio-temporal source characteristics of the 26 December 2004 Sumatra earthquake as imaged by teleseismic broadband arrays, Geophys. Res. Lett., 32, L24312, doi:10.1029/2005GL023939, 2005.

Krüger, F., Rößler, D., and Ohrnberger, M.: Rupture propagation of the July 17, 2006, Mw=7.7 TsE off-coast Java, in: Eos Trans. AGU, vol. 87 of Fall Meet. Suppl., Abstract S21A-0127, 2006.

Neiddell, N. and Turhan Taner, M.: Semblance and other coherency measures for multichannel data, Geophysics, 36, 482-497, 1971.

Ohrnberger, M. and Krüger, F.: Imaging of Large Earthquake Rupture Processes Using Multiple Teleseismic Arrays: Application to the Sumatra-Andaman Island, in: Eos Trans. AGU, vol. 86 of Fall Meet. Suppl., Abstract U11A-0819, 2005.

Rößler, D., Krüger, F., and Ohrnberger, M.: Rupture Propagation of the 2008/05/12 Ms8.0 Wenchuan Earthquake Using Multiple Teleseismic Arrays, in: Eos Trans. AGU, vol. 89 of Fall Meet. Suppl. Abstract S31B-1908, 2008.

Rößler, D., Krüger, F., Ohrnberger, M., and Ehlert, L.: Teleseismic rupture tracking of large earthquakes, online available at: http: //www.uni-potsdam.de, 2009.

Rost, S. and Thomas, C.: Improving Seismic Resolution Through Array Processing Techniques, Surv. Geophys., 30, 271-299, doi: 10.1007/s10712-009-9070-6, 2009.
Rudloff, A., Lauterjung, J., Münch, U., and Tinti, S.: Preface "The GITEWS Project (German-Indonesian Tsunami Early Warning System)", Nat. Hazards Earth Syst. Sci., 9, 1381-1382, 2009, http://www.nat-hazards-earth-syst-sci.net/9/1381/2009/.

Subarya, C., Chlieh, M., Prawirodirdjo, L., Avouac, J.-P., Bock, Y., andA. J. Meltzner, K. S., Natawidjaja, D. H., and McCaffrey, R.: Plate-boundary deformation associated with the great Sumatra Andaman earthquake, Nature, 440, 46-51, doi: 10.1038/nature04522, 2006.

Weber, B., Becker, J., Hanka, W., Heinloo, A., Hoffmann, M., Kraft, T., Pahlke, D., Reinhardt, J., Saul, J., and Thoms, H.: SeisComP3 - automatic and interactive real time data processing, in: Geophysical Research Abstracts, vol. 9 of EGU General Assembly, 2007.

Xu, Y., Koper, K. D., Sufri, O., Zhu, L., and Hutko, A. R.: Rupture imaging of the $M_{w} 7.912$ May 2008 Wenchuan earthquake from back projection of teleseismic $P$ waves, Geochem. Geophy. Geosy., 10, Q04006, doi:10.1029/2008GC002335, 2009.

Zhang, H., Xu, L., Chen, Y., Li, C.-1., and Stammler, K.: Frequencydomain array technique analysis for the rupture duration time and geometrical characteristics of the 2001 Kunlun Mountain Pass earthquake, Acta Seismologica Sinca, 21, 11-23, doi:10.1007/ s11589-008-0011-0, 2008. 